\title{
DIE PASIËNTVORDERINGSVERSLAG AS KOMMUNIKASIEMIDDEL
}

Hierdie artikel het die tweede prys in die kategorie vir geregistreerde verpleegkundiges verower in die 1983 Promex-Curationis skryfkompetisie. Die onderwerp van die kompetisie was kommunikasie in verpleging.

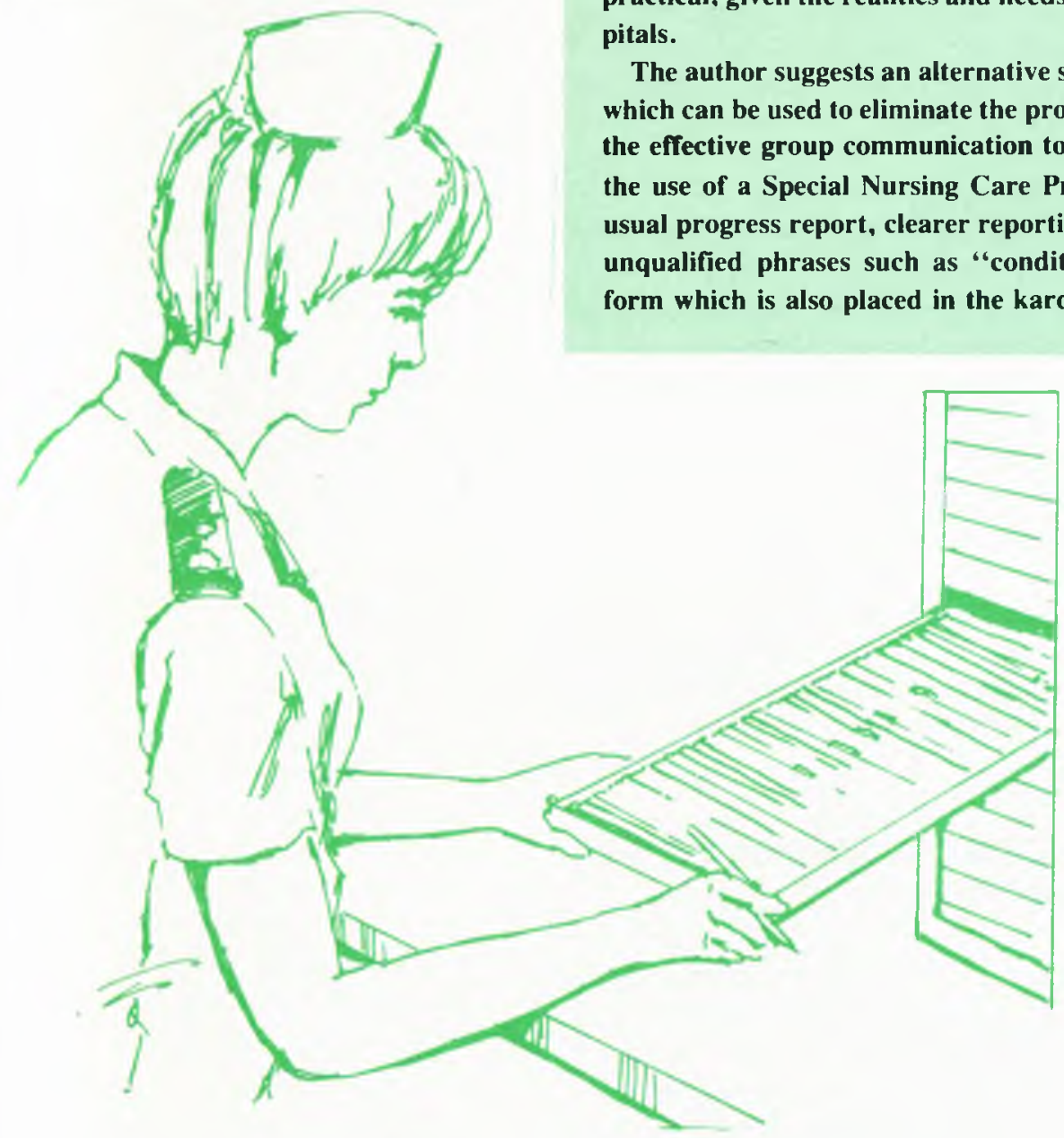

\section{INLEIDING}

Die skep van 'n omgewing van begryping is die eerste en ongetwyfeld die sleutelvoorwaarde vir die daarstelling van 'n milieu van veiligheid waarin die verpleegkundige en ander terapeutise gebeure sigself betekenisvol en effektief sal voltrek. (1:45) Met hierdie stelling het Kotzé verwys na die affektiewe domein van verpleging, maar dieselfde stelling kan gebruik word om te verwys na een van die belangrikste, blywendste en sterkste kommunikasiemiddels in verpleging - die pasiëntvorderingsverslag.

\section{ELDA PRETORIUS}

\section{SUMMARY}

The patient's progress report should be the most important medium of communication in nursing practise. As a result of various factors, however, this report is today often incomplete and not serving its purpose of providing total insight into the progress and treatment of the individual patient.

Possible solutions to the problems encountered are patient-centred nursing care plans and problem oriented progress reports. These are however not always practical, given the realities and needs in most nursing units in South African hospitals.

The author suggests an alternative system, using elements from both the above, which can be used to eliminate the problems and to change the kardex system into the effective group communication tool which it should be. The system includes the use of a Special Nursing Care Prescriptions Card which is placed with the usual progress report, clearer reporting on the patient's condition by eliminating unqualified phrases such as "condition satisfactory" and a special admission form which is also placed in the kardex.

'n Noodsaaklike eienskap van 'n professionele verpleegkundige, wat verantwoordelike besluite moet neem, is die vermoë om te kommunikeer met medepersoneel, geneeshere, para-mediese personeel en die pasiënt. Die pasiëntvorderingsverslag is die groepskommunikasiemiddel tussen verpleegpersoneel, die middel wat effektiewe kommunikasie oor en met die pasiënt moontlik mak. Dit is die begin, die wegspringplek, die fondament van verpleegsorg. Is dié groepskommunikasie gebrekkig, wankelmoedig of ontoereikend, kan daar tog geen sprake van sorg van hoë gehalte wees nie. Dit is die pasiëntvorderingsverslag wat insig bied in die pasiënt se vordering en inligting oor die pasiënt se behandeling gee. Moontlik moet eerder gesê word: dit behoort so te wees, maar dit is nie die geval nie. As dit is hoe u daaroor voel, is u waarskynlik reg en stem u met my saam.

Baie dinge in verpleging het oor die afgelope dekade of wat verander. Een van hierdie aspekte is die wyse van rekordhouding oor 'n pasiënt se sorg en vordering. Onthou u nog die dae van die beveleboek en die verslagboek? Miskien is $u$ te jonk om daarvan te weet, daarom so bietjie meer daaroor.

Dit was 'n onbevredigende en tydrowende metode om voorskrifte en sorg te noteer in die beveleboek (dit was voordat verpleegkundiges besef het dat hulle vennote van die mediese professie is, en bevele ontvang het waar ons vandag mediese voorskrifte ontvang). Met verslagtyd is alles dan weer na die verslagboek oorgedra. Elke pasiënt se naam, registrasienommer en geneesheer moes telkens volledig neergeskryf word. Afgesien van die tydvermorsing deur voortdurende herhaling het ons toe ook in die era van holisme inbeweeg.

'n Holistiese of totale beeld van 'n pasiënt kon slegs met baie moeite verkry word, want elke dag se verslag was op 'n ander bladsy, tussen die van ander pasiënte. 
Hoe wonderlik was die aankoms van die kardexstelsel nie! Duplisering word totaal uitgeskakel en daarmee saam verminder die moontlikheid van foute. Verslagskryf is iets van die verlede, want die inskrywings van die dag. vorm mos die verslag aan die einde van die dag. Elke pasiënt se vorderingsverslag vorm 'n eenheid vanaf die dag van toelating tot met ontslag. Daar was minder tydvermorsing en minder skryfwerk verpleegpersoneel het nou meer tyd om aandag aan hul pasiënte te skenk.

\section{STEEDS TEKORTKOMINGE}

Hoewel die kardexstelsel baie voordele bo die boeke ingehou het, was dit blykbaar nog nie die oplossing vir die rekordhouding oor pasiënte se verpleegsorg en voorskrifte nie. Verskeie probleme het steeds voorgekom:

- geneeshere bly kla dat verpleegkundiges nie aan hulle 'n sinvolle verslag van hul pasiënte kan gee nie:

by herhaling gebeur dit dat pasiënte nie die voorgeskrewe sorg ontvang nie;

- verpleegpersoneel voel self 'n leemte aan en ruim weer 'n tydjie in om verslag te skryf eenmaal in elke 12-uur-periode, addisioneel tot die inskrywings gedurende die periode. Daar word teruggeval na die stereotipe gebruik van stellings soos Goed geslaap, Geen klagte enRoetine sorg verleen. Dit was 'n onbewuste poging om in ongeïdentifiseerde probleem die hoof te bied, maar het steeds 'n leemte gelaat.

\section{OPLOSSINGS}

Verpleegpraktisyns en -leiers het, met reg ook, baie bekommerd geraak oor die situasie. Dit is dan tog nie professionele verpleging wat só lyk nie. Dit skaad die verpleegbeeld geweldig by die mediese professie sowel as by die pasiënte en publiek. Verpleegkundiges raak gefrustreerd en verlaat die beroep. Meer en meer is gepraat van die gebruik van verpleegsorgplanne en probleemgeoriënteerde vorderingsverslae. Die geroep het al luider geword: Weg met die kardex.

Teoreties klink dit heel aanvaarbaar en hoewel min oor probleemgeoriënteerde verslae geskryf is, het al hoe meer literatuur oor verpleegsorgplanne die lig gesien. Daar is egter struikelblokke in die gebruik van hierdie stelsels.
Pasiëntgesentreerde verpleegsorgplanne is sekerlik die ideaal. Dit is egter nie prakties bruikbaar in SuidAfrikaanse hospitale wat steeds beplan en van verpleegpersoneel voorsien word op grond van die beginsel van die funksionele werktoewysing nie.

Pasiëntgesentreerde verpleegsorgplanne vereis dat daar werklik ten volle volgens die spantoewysingsmetode gewerk moet kan word vir 24 uur van die dag. Diensure moet so beplan word dat daar "n oorvleuelingstyd is vir geregistreerde verpleegkundiges wat hulle in staat stel om hul verpleegsorgplanne op te stel of op datum te bring. terwyl daar reeds iemand anders is wat hul verantwoordelikheid van pasiëntsorg kan oorneem. Indien daar sulke eenhede in Suid-Afrika is, is dit die uitsondering en nie die reël nie.

Probleemgeoriënteerde vorderingsverslae rig wel die verpleegkundiges (of soos verpleegleiers sê, $d$ wing verpleegkundiges) om weg te beweeg van stereotipes in verslagskrywing en om oor pasiënte se spesifieke probleme te rapporteer. In die praktyk lei dit egter tot fragmentering van die pasiënt se vorderingsverslag en is dit feitlik nie menslik moontlik om werklik 'n holistiese beeld van 'n pasiënt se sorg en toestand te verkry nie. Beslis nie in beperkte tyd nie - en tyd bly een van die sleutelfaktore vir verpleegkundiges in die kliniese situasie.

\section{OORSAAK VAN KLAGTES EN PROBLEME}

Die oorsaak van die klagtes van geneeshere, tekortkominge in pasiëntsorg en leemtes in pasiëntvorderingsverslae is ' $n$ bose kringloop. Verslaggewing in in normale 24-uur-periode in 'n gewone verpleegeenheid lyk so:

- 07h00: 'n kort en kragtige verslag word oorgegee. (Nagpersoneel gaan immers 07 h00 van diens af en dagpersoneel kom dan eers op diens elkeen gee ' $n$ bietjie en daar is darem 'n tydjie vir verslag). Dit kan 'n swak verslag genoem word maar kom ons noem dit in onvolledige verslag of nog meer beskrywend. "n niksseggende verslag. Kort was dit beslis. maar al wat kragtig daaraan was, is die asemrowende spoed waarmee dit afgehandel is.
Die nagverpleegster het die vorige aand aan diens gekom na 'n rusperiode. Sy het 'n kort en kragtige verslag ontvang van 25 tot 30 pasiënte - almal vir haar totale vreemdelinge. Daar was skaars kans om almal te leer ken, hul medisynes te gee en hul gemaklik te hê vir die nag voordat dit tyd was vir ligte uit. Om 'n totale beeld van enige pasiënt te vorm, en te evalueer hoe daar gevorder word op die pad na optimale gesondheid, is buite die kwessie sonder die behoorlike agtergrond wat 'n volledige en sinvolle verslag aan haar moes oordra. Haar eie verslag weerspieël dus weer net die basiese minimum, net sodat dit darem nie haar onkunde oor haar pasiënte ontbloot nie.

Die verpleegkundige in beheer op dagdiens was naweek af en sy maak kennis met 'n saal vol pasiënte waarvan $50 \%$ vir haar onbekend is. Haar program is vol. Sy moet haar saal organiseer en administreer, pasiënte ontmoet, geneeshere op hul rondtes vergesel, " $n$ beeld kry van haar pasiënte se totale behoeftes en toestand en die sorg wat hulle moet ontvang - dit is alles iewers - op die dieetlys, verbandlys, die bedkaart. en so meer - maar dit neem alles tyd.

- 13h00: Sy het nog steeds nie daarin geslaag om in totale beeld te vorm nie of om kontrole oor en evaluering van pasiëntesorg op 'n professionele wyse uit te voer nie. (Word daar oordryf? Dan staan u beslis nie meer in kliniese praktyk nie en het bietjie vergeet of kontak verloor met die praktiese werklikheid).

Sy dra in kort en kragtige verslag oor aan die nuwe span personeel.Sy poog darem om hierdie kommunikasie meer sinvol te makk. want sy noem darem heelparty van die belangrike aspekte wat sy in die loop van die oggend raakgeloop het. al staan dit dan nou nie in die vorderingsverslae nie. Haar bus vertrek om $13 \mathrm{~h} 15$ en gevolglik kon sy nie te veel tyd afstaan nie. Die nuwe personeel kon nie byhou om alles vir hulself aan te teken nie en kort na sy weg is, is helfte vergete. Om die inligting weer te bekom, is moontlik. maar 'n tydsame proses ..... 


\begin{tabular}{|c|c|c|c|c|c|c|c|c|}
\hline & $\begin{array}{l}\text { Spesiale verpleegsorg } \\
\text { Meu, Sm }\end{array}$ & voorskri & ifte - gebr & vik aanvullend tot kardexka & art as $d$ & eel van pa & $\begin{array}{l}\text { iëntvorderingsverslag. } \\
\text { van der Merwe }\end{array}$ & \\
\hline \begin{tabular}{|l|} 
DATUM \\
\end{tabular} & $\begin{array}{l}\text { MOBILITEIT } \\
\text { EN TOILET }\end{array}$ & \begin{tabular}{|l|} 
PAR. \\
\end{tabular} & DATUM & $\begin{array}{l}\text { DIEET } \\
\text { EN INFUUS }\end{array}$ & $\overline{\text { Par. }}$ & \begin{tabular}{|l} 
DATUM \\
\end{tabular} & $\begin{array}{l}\text { SPESIALE } \\
\text { WAARNEMINGS }\end{array}$ & PAR. \\
\hline $83 / 66 / 01$ & Yol beowas & & $83 / 66 / 01$ & Nul peros & & $83 / 06 / 01$ & $\begin{array}{r}\text { Pols + Bloeddrutk } \\
4 \text {-uurl. }\end{array}$ & \\
\hline & Algehete beorus & GJG/ & & Ive $3 t / 24$ uur & $\cos 6$ & & Temperatuur 4 -wurl. & \\
\hline $83 / 6 / 03$ & Opsit bo $15 \mathrm{~min}$ & SMG & $83 / 06 / 03$ & Helder roeisfowwe & $54 \mathrm{G}$ & & $\begin{array}{r}\text { Portovacsuiging } \\
4-w 4\end{array}$ & \\
\hline $83 / 06 / 04$ & Bedwas met hulp & & $83 / 06 / 04$ & Roostartrood +tee & $G J G / \mathrm{v}$ & & $\begin{array}{c}\text { Portovacoreiponing } \\
4-\text {-url }\end{array}$ & \\
\hline & $\begin{array}{l}\text { Tobriliseer paseñर } \\
\text { Ogsit, stap met hulp }\end{array}$ & $S M G /$ & $83 / 06 / 05$ & Ligto-diëet & SSKG & & $\begin{array}{l}\text { Inname en } \\
\text { Uitskeiding }\end{array}$ & \\
\hline $83 / 60 / 06$ & Ambulant & GJG/ & $83 / 06 / 06$ & Vol dièet & $G G$ & & $\begin{array}{c}\text { Vhaincile } \\
\text { âfokseiding Bd }\end{array}$ & GबG \\
\hline & Was self & SMG & & & & & & \\
\hline & & & & & & & & \\
\hline Datum & FOLEY'S KATETER & PAR. & DATUM & WONDVERSORGING & PaR. & DATUM & ASEMHALING & PAR. \\
\hline $83 / 66$ & Dep 4-uurl & & $83 / 06 / 01$ & $\begin{array}{l}\text { Skoonmagk met } \\
\text { Setrimied 4-uurl }\end{array}$ & $G \bar{J} G / v$ & $83 / 06 / 02$ & $\begin{array}{l}\text { Asemhalings- } \\
\text { oefeninge 4-wurl }\end{array}$ & \\
\hline & $\begin{array}{c}\text { Verwyder 5de dag } \\
(6.6 .83)\end{array}$ & & $83 / 06 / 02$ & $\begin{array}{l}\text { Kerkort dreineringsbui: } \\
2 \mathrm{~cm} \text { daagliks }\end{array}$ & ssk $\mathrm{G} /$ & & $\begin{array}{l}\text { Bisolvon inhalasies } \\
1: 3 \text { t2s } 15 \mathrm{~min}\end{array}$ & \\
\hline & $\begin{array}{l}\text { Bepoar agterblyusende } \\
\text { urine na } 4 \text { ure en }\end{array}$ & & & & & & ¿ Nebulizer & \\
\hline & 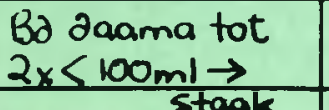 & & & & & & Hoë fowler posisie & $55 k^{g}$ \\
\hline & $>200 \mathrm{ml}$ terug & & & & & & & \\
\hline & vir 48 unr & $G J^{G}$ & & & & & & \\
\hline & & & & & & & & \\
\hline & & & & & & & & \\
\hline
\end{tabular}

Is dit nodig om nog verder te gaan? Dit spreek vanself dat die kringloop net eenvoudig vorm en die pasiëntvorderingsverslag bly onvolledig en 'n swak kommunikasiemiddel.

Voordat 'n alternatiewe oplossing gebied word, behoort eers gekyk te word na wat ons verwag van 'n pasiëntvorderringsverslag wat as primêre kommunikasiemiddel 'n veilige terapeutiese milieu moet verseker. Hoewel die pasiëntvorderingsverslag nie die enigste faktor is wat 'n veilige milieu daarstel nie, is dit die basis, die vertrekpunt.

\section{VEREISTES WAARAAN ' $N$} PASIËNTVORDERINGSVERSLAG MOET VOLDOEN

* Die verslag moet kort wees - omslagtige sinne en 'n opsteleffek moet vermy word.
* Alles moet sinvol wees - onsekerheid oor wat bedoel word moet to die minimum beperk word deur die gebruik van beskrywende terme of kwalifiserende stellings.

* Die verslag moet volledig wees - dit moet 'n geheelbeeld van die pasiënt se toestand, vordering en verpleegsorg weerspieël

* Dit moet verseker dat voorskrifte uitgevoer sal word, ongeag wanneer dit gegee is.

* Dit moet verseker dat basiese sowel as gespesialiseerde sorg nie aan die toeval oorgelaat word nie.

* Dit moet elke verpleegkundige in staat stel om 'n hoë gehalte van verpleegsorg te lewer, vanaf die bekwaamste persoon tot die mees onervare nuweling.

\section{ALTERNATIEWE OPLOSSING}

Deur die gebruik van die alternatiewe oplossing wat hier gebied word, kan die pasiëntvorderingsverslag op eenvoudige wyse omskep word in die werklike kragtige kommunikasiemiddel in verpleegpraktyk wat dit behoort te wees. Dit kan die stewige basis word waarop hoë gehalte verpleegsorg berus.

Met hierdie alternatiewe oplossing word die kardexstelsel as pasiëntvorderingsverslag behou, of ' $n$ ander stelsel wat op die kardexkaart gebaseer is, kan gebruik word. Dus één vorm waarop alle voorskrifte, probleme, behandeling, verpleegsorg en pasiëntvordering noteer word. Die huidige probleme en tekortkominge kan dan uitgeskakel en/of reggestel word met die stelsel wat vervolgens uiteengesit word. 


\section{Spesiale verpleegsorg- voorskrifte-kaart}

Die kardexkaart word aangevul met een addisionele kaart, wat spesiaal vir die doel gedruk is. Hierdie kaart pas in die kardexhouer, teenoor die gewone kaart, en albei is gelyktydig sigbaar. Hierdie kaart word die Spesiale verpleegsorgvoorskrifte genoem. Dit maak voorsiening vir kort duidelike en direkte voorskrifte met betrekking tot spesiale verpleegsorg wat die pasiënt moet ontvang. Wanneer 'n voorskrif gewysig word, word daar eenvoudig 'n potloodstrepie deur die bestaande een getrek en die nuwe voorskrif word daaronder geskryf.

Daar word vir ses verskillende kolomme, voorsiening gemaak waarvan drie van opskrifte voorsien word, naamlik Mobiliteit/Toilet, Dieet/Infuus en Spesiale Waarmenings. Die ander drie kolomme is blanko en word volgens die behoeftes van elke individuele pasiënt gebruik soos vir wondversorging, katetersorg, traksie, inhalasies, en so meer. Tabel 1 is ' $n$ hipotetiese voorbeeld van hoe hierdie kaart gebruik word.

Met een oogopslag kan totale insig van die spesiale verpleegsorgmaatreëls vir elke pasiënt verkry word. Dit rig ook verpleegkundiges waaroor om in die pasientvorderingsverslag van die besondere pasiënt verslag te doen.

Wanneer verslag oorgegee word, moet die verpleegsorgvoorskrifte deel van die verslag wees. Die oorgee van verslag sal nou sinvoller wees en 'n aaneenlopende geheelbeeld bied. Elke nuwe groep personeel sal met 'n deeglike basiese kennis van die pasiënte in hul verpleegeenheid hul diensperiode kan begin. Het iets hul ontgaan, kan die ontbrekende inligting maklik en vinnig weer verkry word omdat dit alles bymekaar is.

\section{Inhoud van verslag}

Daar moet nóg eenmaal in elke 12-uur periode verslag geskryf word. In die verslag word dan net rapporter oor dié aspekte in die spesiale verpleegsorgvoorskrifte waaroor daar nie reeds in die huidige periode ' $n$ aantekening gemaak is nie. Dit behoort die minimum te wees, want in die loop van die periode moet alle voorskrifte en behandelings, medies of verpleegsorg, in die vorderingsverslag aangeteken word soos voorheen ook gedoen is.

'n Verdere punt van belang is dat verpleegpersoneel geleer moet word dat dit wel noodsaaklik is om ook verslag te doen oor die totale toestand van die pasiënt. Dit is waar niksseggende terme soos Rustige dag gehad, Toestand bevredigend en Goed geslaap voorheen gebruik is.

Hiermee word geensins geïnsinueer dat sulke terme taboe is nie. Rus en slaap is immers ' $n$ baie belangrike aspek van die herstelproses en dit is tog noodsaaklik dat daar gemeld moet word of die pasiënt voldoende rus gekry het al dan nie. Dit is net so belangrik dat almal moet weet of die pasiënt se toestand bevredigend is. Juis hier is " $n$ belangrike punt waar ons die pasiëntvorderingsverslag as groepkommunikasiemiddel oor ons pasiënte kan versterk.

Daar moet net besef word dat sulke uitlatings gekwalifiseer of aangevul moet word, sodat almal kan verstaan presies wat daarmee bedoel word. So kan daar dan gesê word: Toestand bevredigend - vitale tekens bly nou stabiel of Vorder goed - kla minder van pyn en beweeg makliker sonder hulp of Toestand onbevredigend - bloeddruk onstabiel of bradikardie nog nie opgehef of Fisiese toestand bevredigend, maar emo. sioneel onstabiel.

Miskien is dit nodig dat iemand 'n lys moet maak van kort beskrywende sinne oor pasiënte se toestand. Verpleegpraktisyns kan dan uit hierdie alternatiewe kies wat by hul pasiënte pas.

Deur aan verpleegkundiges 'n lys van alternatiewe te bied, sal dit hul eie gedagtes stimuleer om later tot eie en dalk meer beskrywende omskrywing van hul pasiënte se toestand te kom. Hulle moet besef dat dit 'n aanduiding moet bied van hoe die pasiënt vorder tot die vlak van optimale gesondheid, die uiteindelike doel van alle verpleegsorg.

\section{Toelatingsvorm}

Om toelating van pasiënte te vergemaklik en te verseker dat al die nodige inligting verkry en aangeteken word, moet 'n spesiale kardex-toelatingsvorm voorsien word. Al die noodsaaklike vrae moet hierop wees, soos allergieë, vorige siektes, medisyne gebruik, vitale tekens en so meer. Andersins kan stempels voorsien word om te gebruik volgens die behoeftes van elke eenheid. So sal dié in kindersale verskil van die in afdelings vir volwassenes.

\section{SLOT}

Effektiewe kommunikasievermoë móét die mees uitstaande eienskap van alle professionele verpleegkundiges wees, sodat hulle in staat is om humanisme binne die wetenskaplike en tegnologiese gesondheidsdiens van die moderne tyd te behou. Hulle moet ook verseker dat die geskrewe woord in verpleegrekordhouding die nodige begrip en terugvoer sal verseker.

Die kombinasie van die pasiëntvorderingsverslag en spesiale verpleegsorgvoorskrifte in die kardexstelsel, bevat aspekte van die probleemgeoriënteerde vorderingsverslag asook van pasiëntgesentreerde verpleegsorgplanne. Dit is aangepas by die praktiese werklikheid en behoeftes in die meerderheid van verpleegeenhede in Suid-Afrikaanse hospitale.

Tot tyd en wyl daar oorhoofse beplanning en voorsiening vir spanverpleging is en die gebruik van rekenaars in verpleegrekordhouding 'n werklikheid word, word die bostaande alternatief voorgehou. Dit is 'n metode om te verseker dat die pasiëntvorderingsverslag as groepkommunikasiemiddel 'n veilige milieu daarstel waarin verpleegkundige en ander terapeutiese gebeure betekenisvol en effektief voltrek sal word.

\section{BIBLIOGRAFIE}

Kotzé. W. (1979) Die hart van verpleging. Curationis Vol 2 No $1 \mathrm{p} 45-46$.

Marram. G.D. et al (1974) Primary nursing - a model for in dividualized care Saint Louis: C V Mosby.

Parsons, R. (1976) The future of the nursing profession: computer technology and clinical nursing practice $S \mathrm{~A}$ Verplegingstydskrif Vol XLIII No 11 p $17-19$

Pluckhan, M.L. (1978) Human communication - the matrix of nursing New York: McGraw-Hill Book Company.

Uys. L.R. (1976) Die verpleegproses en die verpleegsorg plan $S$ A Verplegingstydskrif Vol XLIV No $7 \mathrm{p} 11-14$ Yura. H.: Walsh, M.B. (1978) The Nursing Process New York: Appleton-Century-Crofts. 3rd Ed 